\title{
An improved criterion for new particle formation in diverse atmospheric environments
}

\author{
C. Kuang ${ }^{1,2}$, I. Riipinen ${ }^{3,4}$, S.-L. Sihto ${ }^{4}$, M. Kulmala ${ }^{4}$, A. V. McCormick ${ }^{1}$, and P. H. McMurry ${ }^{2}$ \\ ${ }^{1}$ Department of Chemical Engineering \& Materials Science, University of Minnesota, 151 Amundson Hall, 421 Washington \\ Avenue SE, Minneapolis, Minnesota 55455, USA \\ ${ }^{2}$ Department of Mechanical Engineering, University of Minnesota, 1100 Mechanical Engineering, 111 Church Street SE, \\ Minneapolis, Minnesota 55455, USA \\ ${ }^{3}$ Department of Chemical Engineering, Carnegie Mellon University, 5000 Forbes Avenue, Pittsburg, Pennsylvania 15213, \\ USA \\ ${ }^{4}$ Department of Physics, University of Helsinki, P.O. Box 64, 00014, Helsinki, Finland
}

Received: 2 December 2009 - Published in Atmos. Chem. Phys. Discuss.: 12 January 2010

Revised: 13 July 2010 - Accepted: 30 July 2010 - Published: 8 September 2010

\begin{abstract}
A dimensionless theory for new particle formation (NPF) was developed, using an aerosol population balance model incorporating recent developments in nucleation rates and measured particle growth rates. Based on this theoretical analysis, it was shown that a dimensionless parameter $L_{\Gamma}$, characterizing the ratio of the particle scavenging loss rate to the particle growth rate, exclusively determined whether or not NPF would occur on a particular day. This parameter determines the probability that a nucleated particle will grow to a detectable size before being lost by coagulation with the pre-existing aerosol. Cluster-cluster coagulation was shown to contribute negligibly to this survival probability under conditions pertinent to the atmosphere. Data acquired during intensive measurement campaigns in Tecamac (MILAGRO), Atlanta (ANARChE), Boulder, and Hyytiälä (QUEST II, QUEST IV, and EUCAARI) were used to test the validity of $L_{\Gamma}$ as an NPF criterion. Measurements included aerosol size distributions down to $3 \mathrm{~nm}$ and gas-phase sulfuric acid concentrations. The model was applied to seventyseven NPF events and nineteen non-events (characterized by growth of pre-existing aerosol without NPF) measured in diverse environments with broad ranges in sulfuric acid concentrations, ultrafine number concentrations, aerosol surface areas, and particle growth rates (nearly two orders of magnitude). Across this diverse data set, a nominal value of $L_{\Gamma}=0.7$ was found to determine the boundary for the occur-
\end{abstract}

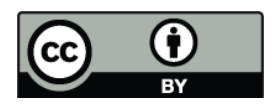

Correspondence to: C. Kuang (ckuang@bnl.gov) rence of NPF, with NPF occurring when $L_{\Gamma}<0.7$ and being suppressed when $L_{\Gamma}>0.7$. Moreover, nearly $45 \%$ of measured $L_{\Gamma}$ values associated with NPF fell in the relatively narrow range of $0.1<L_{\Gamma}<0.3$.

\section{Introduction}

Atmospheric aerosols contribute significantly to the net radiative forcing that drives the earth's energy balance, directly through the scattering and absorption of incident solar radiation, and indirectly through their role as potential cloud condensation nuclei (CCN) (Charlson et al., 1992). New particle formation (NPF), an important source of atmospheric particles, occurs frequently in diverse locations (Kulmala et al., 2004b), and is also an important source of CCN, as demonstrated in various measurement campaigns (Kerminen et al., 2005; Laaksonen et al., 2005) and modeling efforts (Spracklen et al., 2008; Kuang et al., 2009). Since the highest uncertainties in the current estimates for global radiative forcing are associated with these direct and indirect aerosol effects (Chin et al., 2009), it is essential to understand processes that determine new particle formation (NPF) rates.

NPF occurs when nucleated particles grow to a size that can be detected. Until recently, the minimum detectable size was about $3 \mathrm{~nm}$ (Stolzenburg and McMurry, 1991), but recent developments have extended detection limits to sizes below $2 \mathrm{~nm}$ (Kulmala et al., 2007; Iida et al., 2008a; Sipilä et al., 2009). While nucleation potentially occurs every day, NPF only occurs when particle growth to the detection limit

Published by Copernicus Publications on behalf of the European Geosciences Union. 
dominates over particle losses from coagulation with the preexisting aerosol. Analysis with aerosol dynamics models (McMurry and Friedlander, 1979; McMurry, 1983; Kerminen and Kulmala, 2002) have indicated that conditions favorable to NPF include high growth rates and low concentrations of pre-existing aerosol (low scavenging rates). These conditions have also been correlated with measured NPF events observed in diverse field campaigns (Fiedler et al., 2005; McMurry et al., 2005). The development of a simple and universal criterion for NPF would form an important component of predictive models for aerosol formation, and would also quantify the relative importance of these processes that influence aerosol dynamics as they pertain to NPF.

Past and recent efforts to model NPF from the gas-phase have focused on simulating the dynamics of a nucleating aerosol growing through condensation and coagulation (McMurry, 1983; Lehtinen and Kulmala, 2003; Korhonen et al., 2004; Gaydos et al., 2005). In light of the broad range (nearly two orders of magnitude) in the measured nucleation rates, in the pre-existing aerosol surface areas, and in the particle growth rates associated with NPF, it is logical to take a nondimensional approach in modeling NPF so as to obtain universally applicable results. This approach was used by McMurry et al. (1983) in developing a simple dimensionless loss parameter $L$, which is the ratio of the particle loss rate due to scavenging to the particle growth rate, determining whether or not NPF can occur. This parameter $L$ was then calculated for NPF events measured in the sulfur-rich environment of Atlanta where it was shown that NPF was observed when $L<1$ but not when $L>1$ (McMurry et al., 2005).

This original NPF criterion, however, was derived assuming a steady-state, single-component system which greatly limits its application when modeling ambient multicomponent aerosols. Cluster concentrations may not reach steady-state since atmospheric new particle formation is photochemically driven and therefore diurnal and dynamic. The derivation of this $L$ criterion assumed that both nucleation and growth are single-component processes, where every monomer-monomer collision generates a stable cluster (collision-limited nucleation), and where condensation of the monomer (gas-phase sulfuric acid) accounts for all the particle growth. A collision-limited model for nucleation, however, yields particle formation rates that are several orders of magnitude larger than observations (Weber et al., 1996; Kuang et al., 2008). Also, sulfuric acid condensation accounts for only $10 \%$ of the measured particle growth (Weber et al., 1997; Mäkelä et al., 2001; O'Dowd et al., 2002; Wehner et al., 2005; Iida et al., 2008b; Smith et al., 2008). Not only are nucleation and growth multi-component processes, but species that are responsible for the growth of newly formed particles are likely different from those that participate in nucleation. In these environments, the old $L$ criterion greatly underestimates the particle growth rate and consequently underestimates the nucleated particle survival probability and subsequent frequency of NPF.
To address these limitations, we have developed a new aerosol population balance model that predicts new particle formation in a time-dependent system, incorporating recent developments in nucleation rates, parameterizing them as power-law functions of sulfuric acid concentration, (Kulmala et al., 2006; Sihto et al., 2006; Riipinen et al., 2007; Kuang et al., 2008), and recent work in determining the contribution of sulfuric acid condensation to measured nanoparticle growth rates (Birmili et al., 2003; Stolzenburg et al., 2005; Sihto et al., 2006; Riipinen et al., 2007; Iida et al., 2008b). This model adapts a single-component formulation for aerosol dynamics to include a multi-component representation through the use of measured nucleation and growth rates. This model explicitly incorporates the competition between particle loss due to cluster self-coagulation and scavenging by the preexisting aerosol and particle gain due to measured growth, using measured aerosol size distributions and sulfuric acid concentrations. Model analysis yielded a new dimensionless parameter $L_{\Gamma}$, characterizing the ratio of the particle loss rate to the measured particle growth rate, which determined whether or not NPF would occur on a particular day. This criterion $L_{\Gamma}$, determined from measurements of the aerosol size distribution, was validated against seventy-seven NPF events and nineteen non-events (characterized by growth of pre-existing nanoparticles without observed NPF) measured during various campaigns.

\section{Methods}

\subsection{Measurements}

This analysis utilized measurements of aerosol size distributions and gas-phase sulfuric acid concentrations from seventy-seven new particle formation events and nineteen non-events observed during environmentally diverse measurement campaigns: MILAGRO (Tecamac, Mexico) (Iida et al., 2008b), ANARChE (Atlanta, Georgia) (McMurry et al., 2005), Boulder, CO (Iida et al., 2006), QUEST II (Hyytiälä, Finland) (Sihto et al., 2006), QUEST IV (Hyytiälä , Finland) (Riipinen et al., 2007), and an intensive observation period related to the EUCAARI project (Hyytiälä, Finland) (Manninen et al., 2009). Aerosol measurements from the QUEST II, QUEST IV, and EUCAARI campaigns (Kulmala et al., 2009) at the SMEAR II station in Hyytiälä (Hari and Kulmala, 2005) were acquired by the research team from the University of Helsinki while the other aerosol measurements were carried out by the research team from the University of Minnesota. Measurements of gas-phase sulfuric acid concentration were acquired by Frank Arnold of the Max Planck Institute for Nuclear Physics during QUEST II (Sihto et al., 2006) and QUEST IV (Riipinen et al., 2007), by Lee Mauldin of the National Center for Atmospheric Research (NCAR) during EUCAARI (Petäjä et al., 2009), and by Fred Eisele of NCAR for the remaining campaigns (Kuang et al., 2008). 
Descriptions of the physical and meteorological conditions at Tecamac, Atlanta, and Boulder as well as a summary of the pertinent aerosol and gas-phase instrumentation can be found in Kuang et al. (2008).

\subsection{Model development}

Currently, the photochemical nucleation and growth of stable atmospheric clusters is believed to occur through multicomponent processes that often include sulfuric acid. New particle formation occurs when these nucleated clusters grow to a detectable size, typically about $3 \mathrm{~nm}$ (Stolzenburg and McMurry, 1991). The probability of these clusters surviving to $3 \mathrm{~nm}$ depends on the relative rates of cluster growth and loss due to cluster-cluster coagulation and scavenging by the pre-existing aerosol. For a steady-state system, McMurry (1983) developed a simple, limiting criterion for whether or not new particle formation would occur by comparing rates at which clusters grow by condensation and are lost by coagulation with the pre-existing aerosol. It is the goal of this work to extend this criterion to more environmentally diverse systems where other gas-phase species besides sulfuric acid may contribute to growth and nucleation by developing a cluster balance model that explicitly incorporates measurements and observationally constrained parameterizations for growth and nucleation, respectively.

The dynamics of an aerosol driven by simultaneous nucleation, condensation, and coagulation can be described by a set of dimensional population balance equations for discrete cluster sizes $k$ (McMurry, 1983; Lehtinen and Kulmala, 2003):

$$
\begin{aligned}
& \frac{d N_{k^{\dagger}}}{d t}=J^{\dagger}-\beta_{1 k^{\dagger}} N_{1} N_{k^{\dagger}}-N_{k^{\dagger}} \sum_{i=k^{\dagger}}^{\infty} \beta_{k^{\dagger} i} N_{i}-\frac{\bar{c}_{1} A_{\text {Fuchs }}}{4} \frac{N_{k^{\dagger}}}{\sqrt{k^{\dagger}}} \\
& \frac{d N_{k}}{d t}=N_{1}\left(\beta_{1 k-1} N_{k-1}-\beta_{1 k} N_{k}\right)-N_{k} \sum_{i=k}^{\infty} \beta_{k i} N_{i} \\
& +\frac{1}{2} \sum_{\substack{i \geq k^{\dagger} \\
i+j=k}}^{k-k^{\dagger}} \beta_{i j} N_{i} N_{j}-\frac{\bar{c}_{1} A_{\text {Fuchs }}}{4} \frac{N_{k}}{\sqrt{k}}
\end{aligned}
$$

where Eq. (1) is the balance equation for the nucleating critical cluster $\left(k=k^{\dagger}\right)$ and Eq. (2) is the balance equation for clusters larger than the critical cluster $\left(k>k^{\dagger}\right)$. In these equations, $N_{k}$ is the number concentration for newly formed $k$-sized clusters, $N_{1}$ is the number concentration of the condensing vapor-phase species, $\beta_{i j}$ is the collision frequency function between clusters of size $i$ and $j$ (the freemolecular expression is used since the particles of interest are much smaller than the mean free path of air), $A_{\text {Fuchs }}$ is the pre-existing aerosol surface area corrected for diffusion to transition regime particles (Fuchs and Sutugin, 1971) and is calculated according to McMurry et al. (2005), and $\bar{c}_{1}=$ $\sqrt{\left(8 k_{B} T\right) /\left(\pi \rho v_{1}\right)}$ (mean monomer thermal speed) where $v_{1}$ is the molecular volume of the condensing species. While the Fuchs surface area $A_{\text {Fuchs }}$ has been used in Eqs. (1) and (2) to model cluster scavenging, cluster loss to the pre-existing aerosol can also be modeled equally well with the condensation sink CS which uses vapor properties (Kerminen and Kulmala, 2002), or with the coagulation sink CoagS which uses particle properties (Lehtinen et al., 2007). The relationship between $A_{\text {Fuchs }}$ and CS is detailed in McMurry et al. (2005). In Eq. (1), formation of the critical cluster is defined by the nucleation rate $J^{\dagger}$, while depletion occurs through condensational growth past the critical cluster size, cluster-cluster coagulation, and coagulation with the pre-existing aerosol. In Eq. (2), cluster production processes include condensational growth and coagulation of smaller clusters while loss mechanisms include condensational growth of the cluster, clustercluster coagulation, and coagulation with the pre-existing aerosol.

In order to model the cluster dynamics of observed nucleation events, recent developments regarding nucleation rates and growth rates are incorporated into Eqs. (1) and (2). For atmospheric boundary layer nucleation, studies have shown that the nucleation rate can be modeled as a power-law function of the gas-phase sulfuric acid concentration $\left[\mathrm{H}_{2} \mathrm{SO}_{4}\right]$ :

$J^{\dagger}=K\left[\mathrm{H}_{2} \mathrm{SO}_{4}\right]^{P}$

where $K$ is a measurement campaign-specific pre-factor and the exponent $P$ has been shown to vary between 1 and 2 (Weber et al., 1996; Sihto et al., 2006; Riipinen et al., 2007; Kuang et al., 2008). Based on the work of Kuang et al. (2008), a value of $P=2$ and the corresponding pre-factor $K$ are used in this analysis and this power-law expression for nucleation is substituted for $J^{\dagger}$ in Eq. (1). Growth rates based solely on sulfuric acid vapor condensation have been shown to significantly underestimate the measured growth rate (Weber et al., 1997), largely because organic compounds are responsible for up to $90 \%$ of the growth (Mäkelä et al., 2001; O'Dowd et al., 2002; Iida et al., 2008b; Smith et al., 2008). A growth enhancement factor $\Gamma$ is included in Eqs. (1) and (2) as a multiplier of the condensational growth rate due to sulfuric acid in order to capture the condensation of other vaporphase species that contribute to the measured particle growth rate. The growth enhancement factor $\Gamma$ is obtained by dividing the measured growth rate $\mathrm{GR}_{\mathrm{MEAS}}$, by the growth rate assuming free-molecule condensation of sulfuric acid (Weber et al., 1997), yielding the expression:

$\Gamma=\frac{2 \mathrm{GR}_{\mathrm{MEAS}}}{v_{1} N_{1} \bar{c}_{1}}$

where $N_{1}$ is the number concentration of gas-phase sulfuric acid, $v_{1}$ is the corresponding monomer volume estimated to be $1.7 \times 10^{-22} \mathrm{~cm}^{3}$ (the volume occupied by a hydrated $\mathrm{H}_{2} \mathrm{SO}_{4}$ molecule), and $\bar{c}_{1}$ is the mean thermal speed of the condensing monomer. This yields the following cluster population balance equations: 


$$
\begin{aligned}
\frac{d N_{k^{\dagger}}}{d t} & =K N_{1}^{2}-\Gamma \beta_{1 k^{\dagger}} N_{1} N_{k^{\dagger}}-N_{k^{\dagger}} \sum_{i=k^{\dagger}}^{\infty} \beta_{k^{\dagger} i} N_{i} \\
& -\frac{\bar{c}_{1} A_{\text {Fuchs }}}{4} \frac{N_{k^{\dagger}}}{\sqrt{k^{\dagger}}}
\end{aligned}
$$

$$
\begin{aligned}
\frac{d N_{k}}{d t} & =\Gamma N_{1}\left(\beta_{1 k-1} N_{k-1}-\beta_{1 k} N_{k}\right)-N_{k} \sum_{i=k^{\dagger}}^{\infty} \beta_{k i} N_{i} \\
& +\frac{1}{2} \sum_{\substack{i \geq k^{\dagger} \\
i+j=k}}^{k-k^{\dagger}} \beta_{i j} N_{i} N_{j}-\frac{\bar{c}_{1} A_{\text {Fuchs }}}{4} \frac{N_{k}}{\sqrt{k}} .
\end{aligned}
$$

While the growth enhancement factor $\Gamma$ incorporates the effects of multi-component condensation, Eqs. (5) and (6) are still based on a single-component formulation since $\Gamma$ is calculated assuming a condensing molecular volume of hydrated sulfuric acid. The growth enhancement factor $\Gamma$ essentially becomes a multiplier of the sulfuric acid concentration. It is assumed in this analysis that particles throughout the nucleation mode undergo the same enhancement to growth, even though $\Gamma$ is obtained from aerosol measurements larger than $3 \mathrm{~nm}$ and there is evidence that growth rates might depend on particle size (Kulmala et al., 2004a; Hirsikko et al., 2005), which leads to some uncertainty in the growth rate for particles smaller than $3 \mathrm{~nm}$. The extrapolation of growth rates down to growth just after nucleation, however, is not unreasonable, given that growth rates obtained from time-shifts between $\left[\mathrm{H}_{2} \mathrm{SO}_{4}\right]$ and ultrafine particle concentrations are comparable to modal diameter growth rates (growth rates above $3 \mathrm{~nm}$ ) (Fiedler et al., 2005).

With the appropriate dimensional scaling following a method analogous to that of McMurry and Friedlander (1979), Eqs. (5) and (6) can be cast into dimensionless form by making the following substitutions:

$$
\begin{aligned}
& N_{k}=\bar{N}_{k} \sqrt{\frac{K\left(N_{m}\right)^{2}}{\beta_{11}}} \\
& t=\tau \sqrt{\frac{1}{K\left(N_{m}\right)^{2} \beta_{11}}} \\
& \beta_{i j}=c_{i j} \beta_{11} \\
& N_{1}=\bar{N}_{1} N_{m} \\
& L_{1}=\frac{\bar{c}_{1} A_{\text {Fuchs }}}{4 \sqrt{K\left(N_{m}\right)^{2} \beta_{11}}}
\end{aligned}
$$

where $K$ is the pre-factor associated with the nucleation exponent $P=2, N_{m}$ is the peak value of $\left[\mathrm{H}_{2} \mathrm{SO}_{4}\right]$ during the nucleation event, and $L_{1}$ is a dimensionless parameter characterizing the scavenging rate scaled by the maximum nucleation rate $K\left(N_{m}\right)^{2}$. The variables $\bar{N}_{k}, \tau, c_{i j}$, and $\bar{N}_{1}$ are the dimensionless analogues of $N_{k}, t, \beta_{i j}$, and $N_{1}$, where $c_{i j}$ is defined in McMurry and Friedlander (1979); $\beta_{11}$ is the monomer-monomer coagulation coefficient and is calculated assuming a molecular volume of hydrated sulfuric acid. The dimensionless forms of Eqs. (5) and (6) are then:

$$
\begin{aligned}
\frac{d \bar{N}_{k^{\dagger}}}{d \tau} & =\left(\bar{N}_{1}\right)^{2}-\Gamma \sqrt{\frac{\beta_{11}}{K}} c_{1 k^{\dagger}} \bar{N}_{1} \bar{N}_{k^{\dagger}}-\bar{N}_{k^{\dagger}} \sum_{i=k^{\dagger}}^{\infty} c_{k^{\dagger} i} \bar{N}_{i} \\
& -L_{1} \frac{\bar{N}_{k^{\dagger}}}{\sqrt{k^{\dagger}}} \\
\frac{d \bar{N}_{k}}{d \tau} & =\Gamma \sqrt{\frac{\beta_{11}}{K}} \bar{N}_{1}\left(c_{1 k-1} \bar{N}_{k-1}-c_{1 k} \bar{N}_{k}\right)-\bar{N}_{k} \sum_{i=k^{\dagger}}^{\infty} c_{k i} \bar{N}_{i} \\
+ & \frac{1}{2} \sum_{i \geq k^{\dagger}}^{k-k^{\dagger}} c_{i j} \bar{N}_{i} \bar{N}_{j}-L_{1} \frac{\bar{N}_{k}}{\sqrt{k}}
\end{aligned}
$$

where the processes of nucleation, growth, and scavenging are fully decoupled and their effects on the concentration of newly formed particles can be explored. Scaling Eqs. (5) and (6) by the maximum nucleation rate not only reduces the computational load during simulation but also reveals two key dimensionless parameters, $L_{1}$ and $\Gamma_{1}$, where $\Gamma_{1}$ is defined as:

$\Gamma_{1}=\Gamma \sqrt{\frac{\beta_{11}}{K}}$.

The parameters $L_{1}$ and $\Gamma_{1}$ characterize the scavenging and growth processes, respectively, in Eqs. (12) and (13). In subsequent sections, it will be shown that these two parameters provide a strategy to develop a simple, robust criterion for new particle formation.

\subsection{Model application}

Analysis begins by verifying that the set of dimensionless cluster balance Eqs. (12) and (13) can adequately model the measured number concentration $N_{3-4}$, at the detection limit (3-4 nm) during a new particle formation event (Kuang et al., 2008). For a particular event, measured inputs into the model include the peak sulfuric acid concentration $N_{m}$, the corresponding scaled sulfuric acid concentration profile $\bar{N}_{1}$, the growth enhancement factor $\Gamma$, the Fuchs surface area $A_{\text {Fuchs }}$, and the nucleation rate pre-factor $K$. The Fuchs surface area is calculated by integrating over the measured aerosol size distribution according to the method of McMurry et al. (2005). The nucleation rate pre-factor $K$ for each analyzed campaign is obtained from a least-squares fitting of measured $\left[\mathrm{H}_{2} \mathrm{SO}_{4}\right]$ with nucleation rates extrapolated from the particle production rate at the detection limit (Sihto et al., 2006; Riipinen et al., 2007; Kuang et al., 2008). The mass diameter of the critical cluster was assumed to be $1 \mathrm{~nm}$. 
While the pre-factor $K$ is campaign specific, the growth enhancement factor $\Gamma$ is event-specific and is obtained by dividing the measured growth rate by the growth rate assuming only the condensation of sulfuric acid at concentration $N_{m}$. The measured growth rate is estimated from the time delay between $\left[\mathrm{H}_{2} \mathrm{SO}_{4}\right]$ and measured ultrafine particle concentrations (Weber et al., 1997; Fiedler et al., 2005; Sihto et al., 2006; Riipinen et al., 2007; Kuang et al., 2008). Uncertainties associated with the calculation of $\Gamma$ include uncertainties in the measurement of $\left[\mathrm{H}_{2} \mathrm{SO}_{4}\right]$, typically $\pm 50 \%$ (Eisele and Tanner, 1993), and uncertainties in the calculation of the measured growth rate. Because the measured growth rate is determined primarily from the time delay between $\left[\mathrm{H}_{2} \mathrm{SO}_{4}\right]$ and $N_{3-4}$, the resulting uncertainty is based on the time resolution of the measured aerosol size distribution, typically $5 \mathrm{~min}$ (Woo et al., 2001; Stolzenburg et al., 2005). Using this measurement time resolution, a typical growth rate of $5 \mathrm{~nm} / \mathrm{h}$ obtained by time-shift would have an associated uncertainty of $\pm 1 \mathrm{~nm} / \mathrm{h}$. Reasonable relative uncertainties associated with $\Gamma$ would be $\pm 50 \%$. Growth rates from two events in MILAGRO were calculated by analyzing size-dependent charge fractions of 3-25 nm aerosol (Iida et al., 2008b).

Equations (12) and (13) are then solved with the initial condition of $\bar{N}_{k}=0\left(k \geq k^{\dagger}\right)$. The output dimensionless number concentrations $\overline{\bar{N}}_{k}$ are then dimensionalized according to Eq. (7) for comparison with concentration measurements of 3-4 nm mobility diameter particles. The corresponding range in mass diameter is approximately 2.7$3.7 \mathrm{~nm}$, based on the work of $\mathrm{Ku}$ and de la Mora (2009). This conversion between mobility and geometric diameter is necessary when comparing measured and modeled results. Assuming spherical clusters, the cluster sizes $k$ corresponding to this geometric size range are calculated according to the relation (McMurry, 1980):

$$
D_{p}=\left(\frac{6 k v_{1}}{\pi}\right)^{1 / 3} \text {. }
$$

The analysis is simplified by focusing only on the peak values of $N_{3-4}$ when comparing measured and modeled number concentrations. Sensitivity of the modeled $N_{3-4}$ to the peak sulfuric acid concentration $N_{m}$ is explored by using a range of concentrations taken $15 \mathrm{~min}$ before and after the peak sulfuric acid concentration. Uncertainty in the measured peak $N_{3-4}$ is calculated as Poisson error from the finite number of particles detected by the instruments in the corresponding size range. It is expected that the modeled and measured values of peak $N_{3-4}$ would be in qualitative agreement since the nucleation expression that drives the cluster balance in Eq. (5) is parameterized from measured values of $N_{3-4}$.

After model verification, the competing effects of scavenging and growth on new particle formation were explored by calculating the peak dimensionless particle flux $\bar{J}_{3}(3 \mathrm{~nm})$ as a function of parameters $L_{1}$ and $\Gamma_{1}$, which were calculated from the measured ranges in $A_{\text {Fuchs }}, N_{m}$, and growth enhancement factor $\Gamma$ for each measurement campaign. $\bar{J}_{3}$ is defined as:

$$
\bar{J}_{3}=\Gamma \sqrt{\frac{\beta_{11}}{K}} c_{1 k_{3}} \bar{N}_{1} \bar{N}_{k_{3}}
$$

where $k_{3}$ is the cluster size associated with the detection limit at $3 \mathrm{~nm}$ (see Eq. 15). Critical values of $L_{1}$ and $\Gamma_{1}$ at which new particle formation was effectively suppressed were identified from this model analysis and compared with earlier work (McMurry, 1983; McMurry et al., 2005). A dimensionless parameter was then derived based on these critical values of $L_{1}$ and $\Gamma_{1}$, and was subsequently validated as an NPF criterion against measurements of both NPF events and non-events. In this analysis, non-events are characterized by periods where growth of pre-existing nanoparticles was observed but new particle formation was not.

\subsection{Solution procedure}

Following the methods of Rao and McMurry (1989) and Wu and Flagan (1988), Eqs. (12) and (13) are solved via a discrete-sectional method so as to reduce the computational burden when solving a system of cluster population balance equations. In this study, discrete equations were solved for clusters of size $k \leq 100$ (calculated to overlap with the lower detection limit at $3 \mathrm{~nm}$ ), and a sectional representation was used for larger clusters (Gelbard et al., 1980). Numerical diffusion associated with condensation is mitigated by the use of a number conserving expression for condensation fluxes between adjacent sections following the method of Warren and Seinfeld (1985). Accuracy of the discretesectional method when applied to Eqs. (12) and (13) was checked by comparing the numerical and analytical results for the time-dependent cluster number concentrations for the special case of a size-independent collision frequency function. Agreement was within $0.01 \%$. Aerosol dynamic simulations required a typical simulation time of $5 \mathrm{~s}$ per nucleation event. This short computational time enables the efficient exploration of the fairly large parameter space for $L_{1}$ and $\Gamma_{1}$ needed to satisfactorily explore the sensitivity of the particle flux to the measured ranges in scavenging rates and growth rates.

\section{Results and discussion}

Relevant model inputs were obtained from measured aerosol size distributions and $\left[\mathrm{H}_{2} \mathrm{SO}_{4}\right]$ for each analyzed NPF event and are listed in Table 1: $\Gamma$ (event-specific growth enhancement factor), $N_{m}$ (peak $\left[\mathrm{H}_{2} \mathrm{SO}_{4}\right]$ during NPF event), and $A_{\text {Fuchs }}$ (Fuchs aerosol surface area averaged over duration of NPF event). The calculated values of the growth enhancement factor $\Gamma$ span the range from 1 (ANARChE) to over 100 (EUCAARI), illustrating the multi-component nature of particle growth where, depending on location, 
Table 1. Summary of relevant model parameters derived from measured aerosol size distributions and sulfuric acid concentrations for seventy-seven NPF events acquired during the MILAGRO (Tecamac), ANARChE (Atlanta), Boulder, QUEST II (Hyytiälä), QUEST IV (Hyytiälä), and EUCAARI (Hyytiälä) measurement campaigns. See text for parameter descriptions and calculations.

\begin{tabular}{|c|c|c|c|c|c|}
\hline Campaign & $\begin{array}{r}\text { Date } \\
(\mathrm{mm} / \mathrm{dd} / \mathrm{yy})\end{array}$ & $\Gamma$ & $\begin{array}{r}N_{m} \\
\left(\mathrm{~cm}^{-3}\right)\end{array}$ & $\begin{array}{r}A_{\text {Fuchs }} \\
\left(\mu \mathrm{m}^{2} \mathrm{~cm}^{-3}\right)\end{array}$ & $L_{\Gamma}$ \\
\hline \multirow[t]{9}{*}{ MILAGRO } & $03 / 15 / 06$ & 14 & $1.77 \mathrm{E}+07$ & 217 & $1.6 \mathrm{E}-01$ \\
\hline & $03 / 16 / 06$ & 4 & $8.05 \mathrm{E}+07$ & 571 & 3.3E-01 \\
\hline & $03 / 21 / 06$ & 4 & $5.48 \mathrm{E}+07$ & 350 & $3.0 \mathrm{E}-01$ \\
\hline & $03 / 22 / 06$ & 7 & $2.45 \mathrm{E}+07$ & 361 & $3.9 \mathrm{E}-01$ \\
\hline & $03 / 23 / 06$ & 5 & $1.02 \mathrm{E}+08$ & 441 & $1.6 \mathrm{E}-01$ \\
\hline & $03 / 26 / 06$ & 11 & $4.70 \mathrm{E}+07$ & 336 & $1.2 \mathrm{E}-01$ \\
\hline & 03/29/06 & 5 & $2.12 \mathrm{E}+07$ & 207 & 3.7E-01 \\
\hline & $03 / 30 / 06$ & 25 & $1.77 \mathrm{E}+07$ & 208 & 8.8E-02 \\
\hline & 03/31/06 & 7 & $1.73 \mathrm{E}+07$ & 256 & 4.0E-01 \\
\hline \multirow[t]{3}{*}{ ANARChE } & $07 / 31 / 02$ & 1 & $3.58 \mathrm{E}+08$ & 356 & $1.9 \mathrm{E}-01$ \\
\hline & 08/01/02 & 4 & $4.97 \mathrm{E}+07$ & 267 & $2.5 \mathrm{E}-01$ \\
\hline & 08/05/02 & 1 & $2.27 \mathrm{E}+08$ & 266 & 2.2E-01 \\
\hline \multirow[t]{5}{*}{ Boulder } & $09 / 02 / 04$ & 2 & $2.94 \mathrm{E}+07$ & 97 & $3.1 \mathrm{E}-01$ \\
\hline & 09/07/04 & 2 & $3.16 \mathrm{E}+07$ & 122 & $3.6 \mathrm{E}-01$ \\
\hline & 09/08/04 & 5 & $1.69 \mathrm{E}+07$ & 80 & $1.8 \mathrm{E}-01$ \\
\hline & 09/09/04 & 7 & $1.24 \mathrm{E}+07$ & 64 & $1.4 \mathrm{E}-01$ \\
\hline & 09/14/04 & 3 & $2.03 \mathrm{E}+07$ & 90 & 2.8E-01 \\
\hline \multirow[t]{14}{*}{ QUEST II } & $03 / 20 / 03$ & 3 & $3.35 \mathrm{E}+06$ & 10 & $1.9 \mathrm{E}-01$ \\
\hline & $03 / 21 / 03$ & 1 & $6.34 \mathrm{E}+06$ & 19 & $5.6 \mathrm{E}-01$ \\
\hline & $03 / 23 / 03$ & 3 & $3.06 \mathrm{E}+06$ & 22 & 4.5E-01 \\
\hline & $03 / 25 / 03$ & 2 & $4.77 \mathrm{E}+06$ & 11 & 2.2E-01 \\
\hline & $03 / 26 / 03$ & 3 & $6.91 \mathrm{E}+06$ & 40 & $3.6 \mathrm{E}-01$ \\
\hline & $03 / 28 / 03$ & 2 & $3.49 \mathrm{E}+06$ & 8 & $2.1 \mathrm{E}-01$ \\
\hline & $03 / 31 / 03$ & 2 & $3.20 \mathrm{E}+06$ & 15 & 4.4E-01 \\
\hline & $04 / 01 / 03$ & 4 & $5.02 \mathrm{E}+06$ & 23 & 2.1E-01 \\
\hline & $04 / 02 / 03$ & 3 & $5.23 \mathrm{E}+06$ & 36 & 4.3E-01 \\
\hline & $04 / 03 / 03$ & 1 & $1.85 \mathrm{E}+07$ & 48 & 4.9E-01 \\
\hline & $04 / 04 / 03$ & 1 & $6.41 \mathrm{E}+06$ & 12 & $3.5 \mathrm{E}-01$ \\
\hline & $04 / 06 / 03$ & 2 & $3.02 \mathrm{E}+06$ & 12 & 3.7E-01 \\
\hline & $04 / 07 / 03$ & 1 & $1.32 \mathrm{E}+07$ & 16 & 2.3E-01 \\
\hline & 04/08/03 & 2 & $7.16 \mathrm{E}+06$ & 20 & 2.6E-01 \\
\hline \multirow[t]{17}{*}{ QUEST IV } & $04 / 12 / 05$ & 6 & $1.60 \mathrm{E}+07$ & 21 & 4.1E-02 \\
\hline & $04 / 13 / 05$ & 2 & $1.30 \mathrm{E}+07$ & 27 & $1.9 \mathrm{E}-01$ \\
\hline & $04 / 16 / 05$ & 6 & $3.90 \mathrm{E}+06$ & 23 & $1.8 \mathrm{E}-01$ \\
\hline & $04 / 17 / 05$ & 9 & $5.80 \mathrm{E}+06$ & 18 & $6.5 \mathrm{E}-02$ \\
\hline & $04 / 18 / 05$ & 1 & $1.10 \mathrm{E}+07$ & 23 & $3.9 \mathrm{E}-01$ \\
\hline & $04 / 24 / 05$ & 3 & $5.70 \mathrm{E}+06$ & 55 & $6.0 \mathrm{E}-01$ \\
\hline & $04 / 25 / 05$ & 2 & $7.70 \mathrm{E}+06$ & 35 & 4.3E-01 \\
\hline & $04 / 26 / 05$ & 1 & $1.40 \mathrm{E}+07$ & 50 & 6.7E-01 \\
\hline & $04 / 27 / 05$ & 4 & $1.80 \mathrm{E}+07$ & 66 & 1.7E-01 \\
\hline & $04 / 30 / 05$ & 4 & $2.80 \mathrm{E}+06$ & 25 & 4.2E-01 \\
\hline & $05 / 02 / 05$ & 1 & $2.30 \mathrm{E}+07$ & 41 & 3.3E-01 \\
\hline & $05 / 08 / 05$ & 8 & $4.90 \mathrm{E}+06$ & 31 & $1.5 \mathrm{E}-01$ \\
\hline & $05 / 11 / 05$ & 12 & $5.20 \mathrm{E}+06$ & 29 & 8.7E-02 \\
\hline & $05 / 12 / 05$ & 1 & $8.00 \mathrm{E}+06$ & 23 & $5.4 \mathrm{E}-01$ \\
\hline & $05 / 13 / 05$ & 20 & $3.60 \mathrm{E}+06$ & 25 & $6.5 \mathrm{E}-02$ \\
\hline & $05 / 14 / 05$ & 20 & $5.70 \mathrm{E}+06$ & 24 & $3.9 \mathrm{E}-02$ \\
\hline & $05 / 16 / 05$ & 4 & $9.90 \mathrm{E}+06$ & 50 & 2.4E-01 \\
\hline
\end{tabular}

the condensation of sulfuric acid accounts only for a fraction of the measured particle growth. Clearly, as discussed by Smith et al. (2010), there is a need to understand all of the chemical processes that contribute to growth and
Table 1. Continued.

\begin{tabular}{lrrrrr}
\hline Campaign & $\begin{array}{r}\text { Date } \\
(\mathrm{mm} / \mathrm{dd} / \mathrm{yy})\end{array}$ & $\Gamma$ & $\begin{array}{r}N_{m} \\
\left(\mathrm{~cm}^{-3}\right)\end{array}$ & $\begin{array}{r}A_{\text {Fuchs }} \\
\left(\mu \mathrm{m}^{2} \mathrm{~cm}^{-3}\right)\end{array}$ & $L_{\Gamma}$ \\
\hline EUCAARI & $03 / 31 / 07$ & 3 & $2.68 \mathrm{E}+06$ & 11 & $2.6 \mathrm{E}-01$ \\
& $04 / 01 / 07$ & 20 & $2.75 \mathrm{E}+06$ & 13 & $4.4 \mathrm{E}-02$ \\
& $04 / 02 / 07$ & 92 & $2.97 \mathrm{E}+06$ & 11 & $7.5 \mathrm{E}-03$ \\
& $04 / 04 / 07$ & 4 & $3.29 \mathrm{E}+06$ & 10 & $1.4 \mathrm{E}-01$ \\
& $04 / 08 / 07$ & 15 & $2.60 \mathrm{E}+06$ & 11 & $5.3 \mathrm{E}-02$ \\
& $04 / 09 / 07$ & 8 & $4.12 \mathrm{E}+06$ & 25 & $1.4 \mathrm{E}-01$ \\
& $04 / 10 / 07$ & 8 & $1.08 \mathrm{E}+07$ & 39 & $8.5 \mathrm{E}-02$ \\
& $04 / 11 / 07$ & 34 & $2.67 \mathrm{E}+06$ & 7 & $1.4 \mathrm{E}-02$ \\
& $04 / 12 / 07$ & 123 & $2.21 \mathrm{E}+06$ & 11 & $7.6 \mathrm{E}-03$ \\
& $04 / 13 / 07$ & 7 & $2.47 \mathrm{E}+06$ & 20 & $2.2 \mathrm{E}-01$ \\
& $04 / 14 / 07$ & 19 & $2.87 \mathrm{E}+06$ & 21 & $7.2 \mathrm{E}-02$ \\
& $04 / 15 / 07$ & 134 & $2.03 \mathrm{E}+06$ & 40 & $2.8 \mathrm{E}-02$ \\
& $04 / 16 / 07$ & 9 & $4.67 \mathrm{E}+06$ & 88 & $3.9 \mathrm{E}-01$ \\
& $04 / 17 / 07$ & 39 & $9.97 \mathrm{E}+05$ & 26 & $1.3 \mathrm{E}-01$ \\
& $04 / 18 / 07$ & 55 & $1.65 \mathrm{E}+06$ & 24 & $5.0 \mathrm{E}-02$ \\
& $04 / 19 / 07$ & 11 & $1.97 \mathrm{E}+06$ & 19 & $1.6 \mathrm{E}-01$ \\
& $04 / 28 / 07$ & 77 & $1.18 \mathrm{E}+06$ & 9 & $1.9 \mathrm{E}-02$ \\
& $04 / 30 / 07$ & 113 & $2.40 \mathrm{E}+06$ & 12 & $8.3 \mathrm{E}-03$ \\
$05 / 01 / 07$ & 23 & $1.48 \mathrm{E}+06$ & 18 & $9.9 \mathrm{E}-02$ \\
$05 / 05 / 07$ & 121 & $2.25 \mathrm{E}+06$ & 33 & $2.3 \mathrm{E}-02$ \\
& $05 / 06 / 07$ & 77 & $1.77 \mathrm{E}+06$ & 48 & $6.6 \mathrm{E}-02$ \\
$05 / 07 / 07$ & 18 & $1.53 \mathrm{E}+06$ & 75 & $5.1 \mathrm{E}-01$ \\
$05 / 11 / 07$ & 30 & $1.15 \mathrm{E}+06$ & 23 & $1.3 \mathrm{E}-01$ \\
$05 / 13 / 07$ & 17 & $1.09 \mathrm{E}+06$ & 16 & $1.6 \mathrm{E}-01$ \\
$05 / 14 / 07$ & 26 & $5.15 \mathrm{E}+06$ & 56 & $7.8 \mathrm{E}-02$ \\
$05 / 15 / 07$ & 11 & $3.12 \mathrm{E}+06$ & 42 & $2.3 \mathrm{E}-01$ \\
& $05 / 16 / 07$ & 33 & $2.75 \mathrm{E}+06$ & 24 & $5.0 \mathrm{E}-02$ \\
$05 / 17 / 07$ & 12 & $1.38 \mathrm{E}+06$ & 12 & $1.4 \mathrm{E}-01$ \\
$05 / 21 / 07$ & 21 & $3.30 \mathrm{E}+06$ & 67 & $1.8 \mathrm{E}-01$ \\
\hline & & & &
\end{tabular}

that lead to the observed variabilities in $\Gamma$ with time and location. The values of the remaining input parameters also span a wide range $\left(1 \times 10^{6} \mathrm{~cm}^{-3}<N_{m}<4 \times 10^{8} \mathrm{~cm}^{-3}\right.$; $\left.7 \mu \mathrm{m}^{2} \mathrm{~cm}^{-3}<A_{\text {Fuchs }}<570 \mu \mathrm{m}^{2} \mathrm{~cm}^{-3}\right)$; the resulting peak nucleation rate, calculated according to Eq. (3), spans several orders of magnitude. This wide range in the magnitude of source and sink processes emphasizes the need for a dimensionless theory that quantifies the relative contributions of nucleation, cluster growth, cluster-cluster coagulation, and cluster scavenging by the pre-existing aerosol.

\subsection{Model verification}

The modeled and measured peak values of $N_{3-4}$ for each of the analyzed new particle formation events are compared in Fig. 1, with vertical bars representing the sensitivity of the modeled peak $N_{3-4}$ to the measured peak sulfuric acid concentration and with horizontal bars representing the uncertainties associated with particle counts. The modeled and measured peak values of $N_{3-4}$ are in qualitative agreement with each other spanning three orders of magnitude in number concentration for the analyzed measurement campaigns; results from the EUCAARI campaign were not included in Fig. 1. This agreement between model and measurement is somewhat expected since the power-law nucleation model 
used to drive the aerosol dynamics simulation was parameterized from measured ultrafine particle concentrations. Scatter in the modeled peak $N_{3-4}$ (under and over-estimations of the measured $N_{3-4}$ ) can be partially attributed to the use of a single campaign-specific nucleation rate pre-factor $K$, which has an associated confidence interval (Sihto et al., 2006; Riipinen et al., 2007; Kuang et al., 2008). Underestimations of the measured peak $N_{3-4}$ by the model can also be due to the contributions of particle source processes not accounted for in the model (e.g. ion-induced nucleation). In spite of this scatter, this model verification result is significant in that the use of a single campaign-specific $K$ value can reasonably model the peak ultrafine particle concentrations observed at a particular location.

\subsection{NPF criterion development}

After model verification, the effect of scavenging and growth on new particle formation was investigated, focusing primarily on the dimensionless particle flux $\bar{J}_{3}$ as a function of the dimensionless quantities $L_{1}$ (scavenging parameter) and $\Gamma_{1}$ (growth parameter), calculated from measured ranges in $A_{\text {Fuchs }}, N_{m}$, and growth rates. By definition, $\bar{J}_{3}$ is equal to the dimensional particle production rate $J_{3}$ scaled by the dimensional peak nucleation rate, which is a representative value for the probability that a nucleated particle will grow to the detection limit. A contour plot of the modeled peak $\bar{J}_{3}$ as a function of $L_{1}$ and $\Gamma_{1}$ is shown in Fig. 2 for the MILAGRO campaign. This result was obtained using the average of the peak sulfuric acid concentrations measured during the campaign.

Generally, the peak values of $\bar{J}_{3}$ are seen to increase with growth parameter $\Gamma_{1}$ at a given value of scavenging parameter $L_{1}$, and to decrease with $L_{1}$ at a given value of $\Gamma_{1}$. These trends are expected as growth and scavenging are source and sink processes, respectively, for ultrafine particles. From Fig. 2, contours of constant peak $\bar{J}_{3}$ were identified along with their corresponding values of $L_{1}$ and $\Gamma_{1}$. The linearity of each contour over the ranges in $L_{1}$ and $\Gamma_{1}$ suggests a linear $\log$-log relationship between $L_{1}$ and $\Gamma_{1}$ for a given value of $\bar{J}_{3}: \log L_{1}=M \log \Gamma_{1}+B$, where $M$ and $B$ are leastsquares fit parameters obtained for each value of $\bar{J}_{3}$. Leastsquares analysis yielded an average $M$ value of $1.03 \pm 0.02$ ( $95 \%$ confidence) over the range of modeled peak $\bar{J}_{3}$. With $M$ essentially equal to one, the parameter $B$ is then equal to $\log \left(L_{1} / \Gamma_{1}\right)$. Since each line of constant $\bar{J}_{3}$ has a unique intercept $B, \bar{J}_{3}$ is then seen to depend only on $\log \left(L_{1} / \Gamma_{1}\right)$ or, alternatively, on the ratio $L_{1} / \Gamma_{1}$. Each value of $\bar{J}_{3}$ has a unique value of $L_{1} / \Gamma_{1}$, and vice versa. This result suggests that the effect of cluster-cluster coagulation (as both a source and sink process from Eqs. (12) and (13) contributes negligibly to the evolution of the cluster distribution. Identical behavior was also observed in the model results for the other measurement campaigns. The apparent inconsistency of this result with the observation that substantial co-

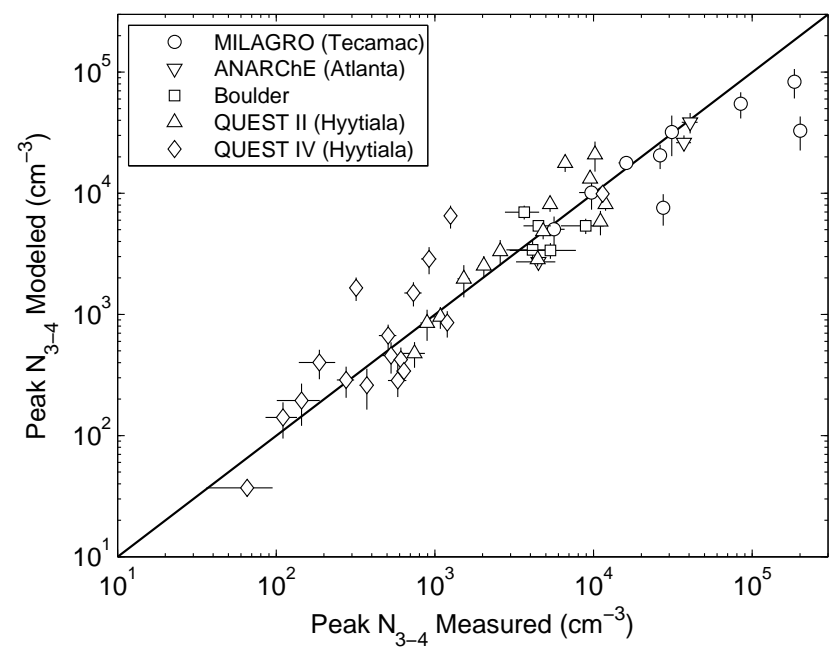

Fig. 1. Comparison of measured and modeled peak ultrafine particle number concentrations $\left(\mathrm{N}_{3}-4\right)$ for forty-eight new particle formation events measured during the field campaigns (location) listed in the figure legend; results from EUCAARI are not included. The solid diagonal line represents perfect agreement between model results and measurements. Vertical and horizontal bars represent measured ranges associated with the maximum sulfuric acid concentration and uncertainties associated with the measured particle counts, respectively.

agulation was observed in Atlanta (Stolzenburg et al., 2005) and Mexico City (Kuang et al., 2009) is resolved by noticing that the contribution of coagulation is a strong function of cluster size. The contribution of cluster-cluster coagulation would be nearly negligible up to the detection limit, yet would be significant at larger sizes. A more detailed analysis of the contribution of cluster-cluster coagulation to the cluster survival probability will be included in a subsequent paper focusing on intercomparisons between nucleation rate parameterizations (Weber et al., 1997; Kerminen and Kulmala, 2002; Lehtinen et al., 2007).

The negligible contribution of cluster-cluster coagulation to the evolution of the size distribution and the result that $\bar{J}_{3}$ depends only on the ratio $L_{1} / \Gamma_{1}$ (hereafter renamed $L_{\Gamma}$ ) indicates that $L_{\Gamma}$ is the controlling parameter that exclusively determines the probability that a nucleated particle grows to the detection limit. $L_{\Gamma}$ is the ratio of the scavenging loss rate to the growth rate and, from Eqs. (11) and (14), is defined as:

$L_{\Gamma}=\frac{L_{1}}{\Gamma_{1}}=\frac{\bar{c}_{1} A_{\text {Fuchs }}}{4 \Gamma \beta_{11} N_{m}}=\frac{L}{\Gamma}$

where $L$ is the expression given by McMurry (1983). $L$ was reasonably successful in predicting the occurrence of NPF in the sulfur-rich environment of Atlanta during the ANARChE measurement campaign. There, it was shown that sulfuric acid condensation accounted for nearly all of the growth early in the nucleation event. Under those conditions, the growth enhancement factor $\Gamma$ is equal to one (see Table 1) 


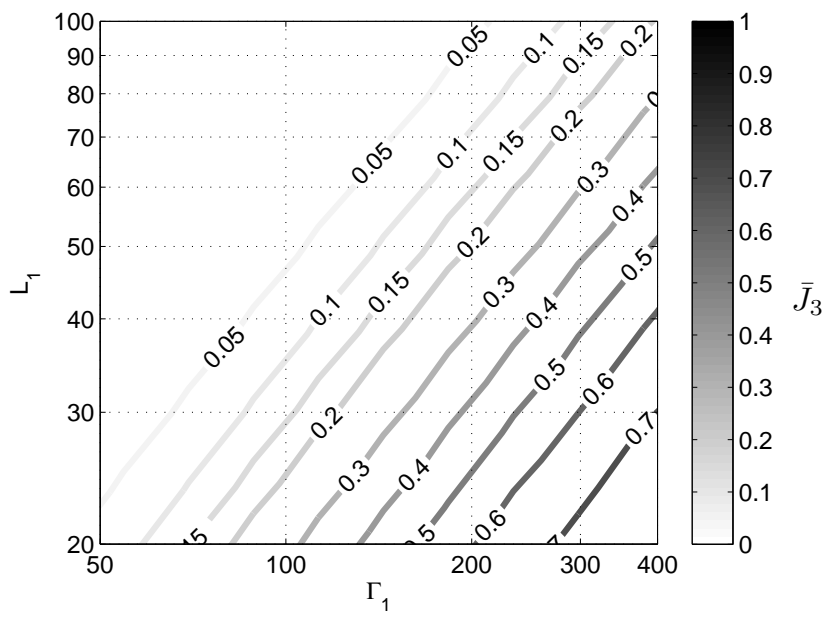

Fig. 2. Contour plot of modeled peak $\bar{J}_{3}(0.05-0.70)$ as a function of measured ranges in the dimensionless cluster scavenging parameter $L_{1}$ and dimensionless cluster growth parameter $\Gamma_{1}$ for the MILAGRO campaign (Tecamac). $\bar{J}_{3}$ is equal to the survival probability of a nucleated particle growing to the detection limit $(3 \mathrm{~nm})$.

and the parameters $L_{\Gamma}$ and $L$ become identical. The advantage of this new parameter $L_{\Gamma}$ is that it is derived from a more general form of the aerosol population balance equations that explicitly incorporates the observed ranges in experimentally parameterized nucleation rates and measured growth rates. It is worth noting that $L_{\Gamma}$ is independent of the nucleation rate pre-factor $K$ and nucleation exponent $P$ from Eq. (3). Therefore, any nucleation rate expression of the form $J^{\dagger}=K\left[\mathrm{H}_{2} \mathrm{SO}_{4}\right]^{P}$ can be used to drive the aerosol dynamics simulation in Eqs. (12) and (13), as long as the nucleation rate magnitudes are constrained to ambient values. All that is required to calculate $L_{\Gamma}$, however, is the aerosol Fuchs surface area and the particle growth rate, both of which can be obtained directly from measurements of the aerosol size distribution.

With $L_{\Gamma}$ as the controlling parameter, the results from Fig. 2 can then be recast in a more compact form, where the modeled peak $\bar{J}_{3}$ is now plotted only as a function of $L_{\Gamma}$ for each measurement campaign, as shown in Fig. 3. The results from each campaign at each value of $L_{\Gamma}$ are nearly identical, deviating by less than $5 \%$ from each other. This similarity is a remarkable result given that the measured inputs into the model vary over several orders of magnitude across the different campaigns. This location-independent result further indicates that the contribution of cluster-cluster coagulation up to $3 \mathrm{~nm}$ is nearly negligible, even in polluted environments like Tecamac and Atlanta, where significant coagulation might have been expected to occur. From Fig. 3, $\bar{J}_{3}$ is seen to asymptotically approach unity in the limit of $L_{\Gamma} \ll 1$, which is consistent with the fact that at fast enough growth rates $\left(\Gamma_{1} \gg L_{1}\right)$, nearly all nucleated particles survive to $3 \mathrm{~nm}$ and the particle flux at the detection limit ap-

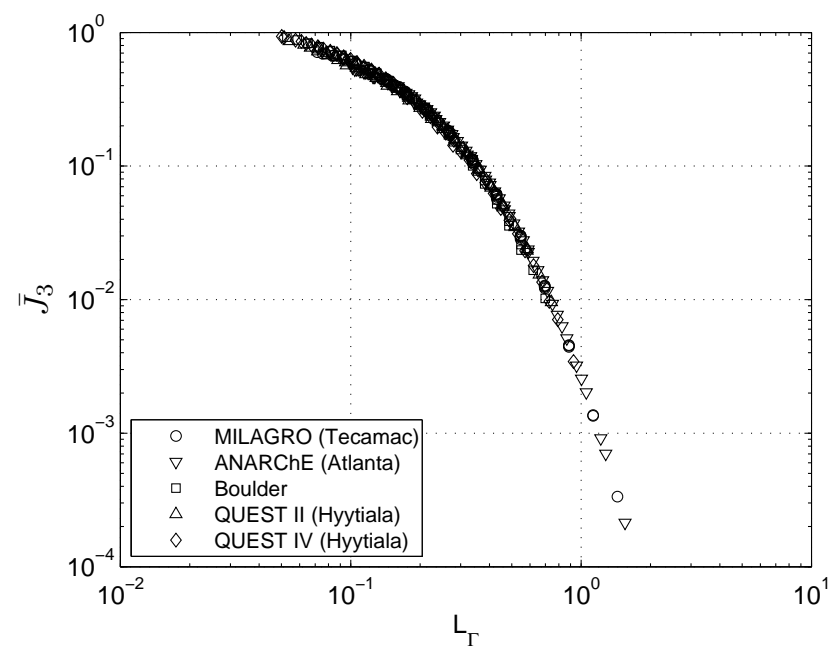

Fig. 3. Modeled peak $\bar{J}_{3}$ as a function of $L_{\Gamma}\left(L_{\Gamma}=L_{1} / \Gamma_{1}\right)$ for the analyzed measurement campaigns (locations), where $L_{1}$ is the dimensionless cluster scavenging parameter (Eq. 11) and $\Gamma_{1}$ is the dimensionless cluster growth parameter (Eq. 14).

proaches the nucleation rate. $\bar{J}_{3}$ is also seen to decrease with increasing $L_{\Gamma}\left(L_{1} \gg \Gamma_{1}\right)$, approaching a survival probability of $0.2 \%$ at $L_{\Gamma}=1$, where new particle formation is effectively suppressed. Based on this model result, new particle formation would then occur only for values of $L_{\Gamma}<1$.

This limiting criterion was then tested against measured new particle formation events by calculating $L_{\Gamma}$ from the scavenging and growth parameters, $L_{1}$ and $\Gamma_{1}$, respectively, associated with the peak $N_{3-4}$ for each of the seventy-seven new particle formation events that were analyzed. The $L_{\Gamma}$ values for each analyzed NPF event are included in Table 1 , ranging from $0.0075-0.66 . L_{\Gamma}$ values were also calculated for nineteen non-events where nanoparticle growth of the pre-existing aerosol was observed but NPF was not. Only nineteen of these non-events were identified due to the analysis requirement of measurable growth of the preexisting aerosol mode so that a growth enhancement factor $\Gamma$ could be obtained. The value of $N_{m}$ associated with a particular non-event was determined by taking the maximum value of $\left[\mathrm{H}_{2} \mathrm{SO}_{4}\right]$ measured during the period in which there was observable growth of the pre-existing aerosol. Relevant measured parameters and resulting $L_{\Gamma}$ values for these non-events are detailed in Table 2, with values of the growth enhancement factor $\Gamma$ ranging from $3-100, N_{m}$ ranging from $6 \times 10^{4}-2 \times 10^{6} \mathrm{~cm}^{-3}, A_{\text {Fuchs }}$ ranging from 10-300 $\mu \mathrm{m}^{2} \mathrm{~cm}^{-3}$, and $L_{\Gamma}$ ranging from 0.76-9.4. The importance of these non-events where pre-existing aerosol growth occurs without detectable NPF has not been discussed in the literature and represents a crucial subset of aerosol measurements against which the $L_{\Gamma}>1$ criterion (where NPF is suppressed) can be tested. Without such observations, only half of the NPF criterion can be verified. The results from this analysis are shown as a histogram in Fig. 4 , where $L_{\Gamma}$ values 
Table 2. Summary of relevant model parameters derived from measured aerosol size distributions and sulfuric acid concentrations for nineteen non-events, characterized by the growth of pre-existing nanoparticles without new particle formation, acquired during the ANARChE (Atlanta), Boulder, QUEST II (Hyytiälä), QUEST IV (Hyytiälä), and EUCAARI (Hyytiälä) measurement campaigns. See text for parameter descriptions and calculations.

\begin{tabular}{lrrrrr}
\hline Campaign & $\begin{array}{r}\text { Date } \\
(\mathrm{mm} / \mathrm{dd} / \mathrm{yy})\end{array}$ & $\Gamma$ & $\begin{array}{r}N_{m} \\
\left(\mathrm{~cm}^{-3}\right)\end{array}$ & $\begin{array}{r}A_{\text {Fuchs }} \\
\left(\mu \mathrm{m}^{2} \mathrm{~cm}^{-3}\right)\end{array}$ & $L_{\Gamma}$ \\
\hline ANARChE & $08 / 07 / 02$ & 3 & $2.01 \mathrm{E}+06$ & 304 & $9.5 \mathrm{E}+00$ \\
\hline Boulder & $06 / 11 / 04$ & 4 & $6.99 \mathrm{E}+05$ & 34 & $2.3 \mathrm{E}+00$ \\
\hline QUEST II & $03 / 30 / 03$ & 31 & $2.07 \mathrm{E}+05$ & 121 & $3.5 \mathrm{E}+00$ \\
& $04 / 05 / 03$ & 5 & $4.32 \mathrm{E}+05$ & 19 & $1.6 \mathrm{E}+00$ \\
\hline QUEST IV & $04 / 28 / 05$ & 5 & $2.56 \mathrm{E}+06$ & 112 & $1.6 \mathrm{E}+00$ \\
& $05 / 01 / 05$ & 9 & $4.78 \mathrm{E}+05$ & 29 & $1.3 \mathrm{E}+00$ \\
& $05 / 15 / 05$ & 4 & $6.16 \mathrm{E}+05$ & 10 & $7.6 \mathrm{E}-01$ \\
\hline EUCAARI & $03 / 26 / 07$ & 15 & $1.37 \mathrm{E}+06$ & 131 & $1.2 \mathrm{E}+00$ \\
& $04 / 20 / 07$ & 26 & $1.23 \mathrm{E}+05$ & 18 & $1.1 \mathrm{E}+00$ \\
& $04 / 23 / 07$ & 19 & $4.17 \mathrm{E}+05$ & 44 & $1.0 \mathrm{E}+00$ \\
& $04 / 24 / 07$ & 23 & $8.00 \mathrm{E}+04$ & 38 & $3.9 \mathrm{E}+00$ \\
& $04 / 25 / 07$ & 87 & $6.18 \mathrm{E}+04$ & 46 & $1.6 \mathrm{E}+00$ \\
& $05 / 08 / 07$ & 10 & $2.35 \mathrm{E}+05$ & 55 & $4.4 \mathrm{E}+00$ \\
& $05 / 09 / 07$ & 43 & $2.25 \mathrm{E}+05$ & 63 & $1.2 \mathrm{E}+00$ \\
& $05 / 12 / 07$ & 24 & $1.10 \mathrm{E}+05$ & 21 & $1.5 \mathrm{E}+00$ \\
& $05 / 23 / 07$ & 35 & $1.60 \mathrm{E}+05$ & 54 & $1.8 \mathrm{E}+00$ \\
& $05 / 24 / 07$ & 50 & $1.52 \mathrm{E}+05$ & 54 & $1.3 \mathrm{E}+00$ \\
& $05 / 26 / 07$ & 107 & $1.60 \mathrm{E}+05$ & 146 & $1.6 \mathrm{E}+00$ \\
& $05 / 28 / 07$ & 83 & $1.13 \mathrm{E}+05$ & 117 & $2.3 \mathrm{E}+00$ \\
\hline
\end{tabular}

associated with NPF events and non-events are displayed. The range in $L_{\Gamma}$ values for NPF events $(0.0075-0.66)$ correspond to survival probabilities in the range $2-100 \%$, while $L_{\Gamma}$ values for non-events (0.76-9.4) correspond to survival probabilities much less than $1 \%$. The majority of $L_{\Gamma}$ values associated with NPF events fell well below the $L_{\Gamma}=0.7$ boundary, where the model predicts NPF should occur. Conversely, the majority of $L_{\Gamma}$ values associated with non-events fell well above the boundary $L_{\Gamma}=0.7$, where the model predicts NPF should be suppressed.

This universal behavior across different measurement campaigns for both NPF events and non-events indicates that $L_{\Gamma}$ is a robust parameter that can potentially be used to predict the frequency and relative strength of NPF events. At a particular location, fairly reasonable estimates of the preexisting aerosol surface area can be made, as seen from the relatively narrow range of $A_{\text {Fuchs }}$ values in Table 1 . While there can be a wide range in values of the growth enhancement factor $\Gamma$ for certain locations (e.g. Hyytiala), there is also evidence that NPF events can be characterized by a relatively narrow range in $\Gamma$ at sites such as Atlanta, Boulder, and Mexico City. The predictive power of this criterion will improve as better estimates are made regarding nanoparticle growth rates.

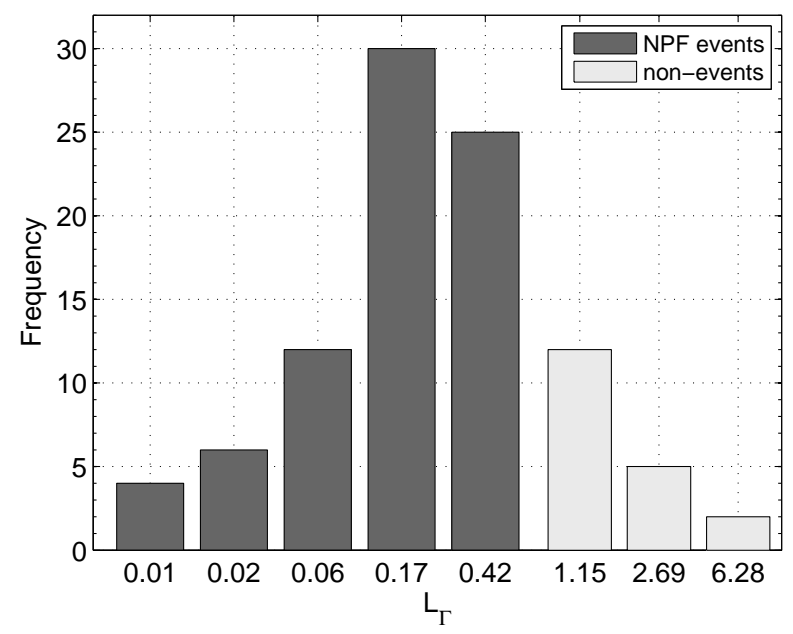

Fig. 4. Histogram of measured $L_{\Gamma}$ values associated with seventyseven NPF events and nineteen non-events from the MILAGRO (Tecamac), ANARChE (Atlanta), Boulder, QUEST II (Hyytiälä), QUEST IV (Hyytiälä), and EUCAARI (Hyytiälä) measurement campaigns. $L_{\Gamma}=L_{1} / \Gamma_{1}$, where $L_{1}$ is the dimensionless cluster scavenging parameter (Eq. (11) and $\Gamma_{1}$ is the dimensionless cluster growth parameter (Eq. 14). Values of $L_{\Gamma}$ are binned on a logarithmic scale, ranging from $0.0075-0.66$ for NPF events and from 0.76-9.4 for non-events, and are listed for each campaign in Tables 1 and 2, respectively.

$L_{\Gamma}$ values for nearly $45 \%$ of the NPF events span the relatively narrow range $0.1<L_{\Gamma}<0.3$, corresponding to a probability between $10 \%$ and $50 \%$ that a nucleated particle will grow to $3 \mathrm{~nm}$. This narrow range suggests a self-regulating process in the boundary layer where high growth rates for sub $3 \mathrm{~nm}$ particles, which enhance survival probability, are often accompanied by a large pre-existing aerosol surface area, which depletes the newly formed particle population and decreases the survival probability, as observed in Tecamac and vice versa as observed in Hyytiälä. Analogous selfregulating behavior for the production of $\mathrm{CCN}(\sim 100 \mathrm{~nm})$ from newly formed particles was observed in simulation results (Spracklen et al., 2008) and constrained models (Kuang et al., 2009).

To accurately predict NPF, it is imperative to incorporate the measured enhancement to the particle growth rate $\Gamma$ (the ratio of the measured growth rate to the growth rate assuming only sulfuric acid condensation), since $L_{\Gamma}$ scales with $1 / \Gamma$. Assuming that sulfuric acid condensation is responsible for all the growth $(\Gamma=1)$ leads to an overestimation of $L_{\Gamma}$ by a factor of 10 , since $\Gamma$ is typically $\sim 10$ for measured NPF events. For NPF events with $L_{\Gamma}$ values greater than 0.07 ( $\sim 80 \%$ of analyzed NPF events), assuming that sulfuric acid condensation accounts for all the growth $(\Gamma=1)$ yields $L_{\Gamma}$ values that are greater than 0.7 , where NPF is not predicted to occur. The systematic division of the data based on $L_{\Gamma}$ also indicates that at the studied sites, the growth of freshly-nucleated particles practically always needs to be 
enhanced by other components than sulfuric acid - even at particle sizes smaller than $3 \mathrm{~nm}$ - in order for NPF to be detected. In the case of Hyytiälä, this observation is consistent with sub-3 nm growth rate observations (Hirsikko et al., 2005) as well as the indirect observations of the wateraffinity of the sub $-3 \mathrm{~nm}$ particles in Hyytiälä (Riipinen et al., 2009). Therefore, assuming that sulfuric acid accounts for all the measured growth leads to a dramatic underestimation of both the frequency of NPF events and the associated particle production rates.

\section{Conclusions}

A dimensionless cluster population balance model was developed to analyze new particle formation from a nucleating system growing by condensation and coagulation in the presence of a pre-existing aerosol. The model incorporates recent developments in nucleation rates parameterized as power-law functions of gas-phase sulfuric acid and recent work in nanoparticle growth rates. Model results were validated against measured new particle formation events, yielding good agreement between modeled and measured ultrafine particle number concentrations. Model analysis indicated that nucleated particle survival probability depends only on a simple dimensionless parameter $L_{\Gamma}$. This parameter describes the ratio between scavenging of newly formed particles by the pre-existing aerosol to the growth rate of newly formed particles. $L_{\Gamma}$ was shown to determine exclusively whether or not new particle formation could occur on a particular day and was validated against seventy-seven NPF events and nineteen non-events characterized by measurable growth of pre-existing nanoparticles without NPF. New particle formation was shown to occur only at values of $L_{\Gamma}<0.7$ where low scavenging rates and high growth rates enabled nuclei to survive to a detectable size. NPF was suppressed for values of $L_{\Gamma}>0.7$. For NPF events, measured values of $L_{\Gamma}$ and corresponding survival probabilities fell in a relatively narrow range, suggesting a self-regulating process in the boundary layer where enhancements from high growth rates are mitigated by depletions from a substantial pre-existing aerosol surface area, and vice versa. Although the absolute values of $L_{\Gamma}$ are affected by experimental uncertainties and the assumptions of critical cluster size and condensing vapor properties, our results show that the same unique criterion for the occurrence of NPF applies in diverse environments.

Acknowledgements. Financial support from the National Science Foundation (DGE-0114372 and ATM-050067), the Department of Energy (DE-FG02-05ER63997), the Guggenheim Foundation (PHM), and the Academy of Finland (MK), and computational resources from the Minnesota Supercomputing Institute are gratefully acknowledged.

Edited by: W. Birmili

\section{References}

Birmili, W., Berresheim, H., Plass-Dülmer, C., Elste, T., Gilge, S., Wiedensohler, A., and Uhrner, U.: The Hohenpeissenberg aerosol formation experiment (HAFEX): a longterm study including size-resolved aerosol, $\mathrm{H} 2 \mathrm{SO} 4, \mathrm{OH}$, and monoterpenes measurements, Atmos. Chem. Phys., 3, 361-376, doi:10.5194/acp-3-361-2003, 2003.

Charlson, R. J., Schwartz, S. E., Hales, J. M., Cess, R. D., Coakley, J. A., Hansen, J. E., and Hofmann, D. J.: Climate forcing by anthropogenic aerosols, Science, 255, 423-430, 1992.

Chin, M., Kahn, R. A., Remer, L. A., Yu, H., Rind, D., Feingold, G., Quinn, P. K., Schwartz, S. E., Streets, D. G., Decola, P., and Halthore, R.: Atmospheric Aerosol Properties and Climate Impacts, in: U.S. Climate Change Science Program Synthesis and Assessment Product 2.3, 2009.

Eisele, F. L. and Tanner, D. J.: Measurement of the gas phase concentration of $\mathrm{H}_{2} \mathrm{SO}_{4}$ and methane sulfonic acid and estimates of $\mathrm{H}_{2} \mathrm{SO}_{4}$ production and loss in the atmosphere, J. Geophys. Res.Atmos., 98, 9001-9010, 1993.

Fiedler, V., Dal Maso, M., Boy, M., Aufmhoff, H., Hoffmann, J., Schuck, T., Birmili, W., Hanke, M., Uecker, J., Arnold, F., and Kulmala, M.: The contribution of sulphuric acid to atmospheric particle formation and growth: a comparison between boundary layers in Northern and Central Europe, Atmos. Chem. Phys., 5, 1773-1785, doi:10.5194/acp-5-1773-2005, 2005.

Fuchs, N. A. and Sutugin, A. G.: High-dispersed aerosols, in: Topics in Current Aerosol Research, edited by: Hidy, G. M. and Brock, J. R., Pergamon, Oxford, 1-60, 1971.

Gaydos, T. M., Stanier, C. O., and Pandis, S. N.: Modeling of in situ ultrafine atmospheric particle formation in the eastern United States, J. Geophys. Res., 110, D07S12, doi:10.1029/2004JD004683, 2005.

Gelbard, F., Tambour, Y., and Seinfeld, J. H.: Sectional representations for simulating aerosol dynamics, Journal of Colloid and Interface Science, 76, 541-556, 1980.

Hari, P. and Kulmala, M.: Station for measuring ecosystematmosphere relations (SMEAR II), Boreal Environ. Res., 10, 315-322, 2005.

Hirsikko, A., Laakso, L., Horrak, U., Aalto, P. P., Kerminen, V., and Kulmala, M.: Annual and size dependent variation of growth rates and ion concentrations in boreal forest, Boreal Enviro. Res., 10, 357-369, 2005.

Iida, K., Stolzenburg, M., McMurry, P., Dunn, M. J., Smith, J. N., Eisele, F., and Keady, P.: Contribution of ion-induced nucleation to new particle formation: methodology and its application to atmospheric observations in Boulder, Colorado, J. Geophys. Res., 16(D23), D23201, doi:10.1029/2006JD007167, 2006.

Iida, K., Stolzenburg, M. R., and McMurry, P. H.: Effect of working fluid on sub- $2 \mathrm{~nm}$ particle detection with a laminar flow ultrafine condensation particle counter, Aerosol Sci. Technol., 43, 81-96, doi:10.1080/02786820802488194, 2008a.

Iida, K., Stolzenburg, M. R., McMurry, P. H., and Smith, J. N.: Estimating nanoparticle growth rates from size-dependent charged fractions: analysis of new particle formation events in Mexico City, J. Geophys. Res., 15, D05207, doi:10.1029/2007JD009260, 2008b.

Kerminen, V. M. and Kulmala, M.: Analytical formulae connecting the "real" and the "apparent" nucleation rate and the nuclei number concentration for atmospheric nucleation events, J. Aerosol 
Sci., 33, 609-622, 2002.

Kerminen, V. M., Lihavainen, H., Komppula, M., Viisanen, Y., and Kulmala, M.: Direct observational evidence linking atmospheric aerosol formation and cloud droplet activation, Geophys. Res. Lett., 14(32), L14803, doi:10.1029/2007JD009260, 2005.

Korhonen, H., Lehtinen, K. E. J., and Kulmala, M.: Multicomponent aerosol dynamics model UHMA: model development and validation, Atmos. Chem. Phys., 4, 757-771, doi:10.5194/acp-4757-2004, 2004.

$\mathrm{Ku}, \mathrm{B} . \mathrm{K}$. and de la Mora, J. F.: Relation between electrical mobility, mass, and size for nanodrops $1-6.5 \mathrm{~nm}$ in diameter in air, Aerosol Sci. Technol., 43, 241-249, 2009.

Kuang, C., McMurry, P. H., McCormick, A. V., and Eisele, F. L.: Dependence of nucleation rates on sulfuric acid vapor concentration in diverse atmospheric locations, J. Geophys. Res., 110, D10209, doi:10.1029/2007JD009253, 2008.

Kuang, C., McMurry, P. H., and McCormick, A. V.: Determination of cloud condensation nuclei production from measured new particle formation events, Geophys. Res. Lett., 36, L09822, doi:10.1029/2009GL037584, 2009.

Kulmala, M., Laakso, L., Lehtinen, K. E. J., Riipinen, I., Dal Maso, M., Anttila, T., Kerminen, V.-M., Hõrrak, U., Vana, M., and Tammet, H.: Initial steps of aerosol growth, Atmos. Chem. Phys., 4, 2553-2560, doi:10.5194/acp-4-2553-2004, 2004a.

Kulmala, M., Vehkamäki, H., Petäjä, T., Dal Maso, M., Lauri, A., Kerminen, V. M., Birmili, W., and McMurry, P. H.: Formation and growth rates of ultrafine atmospheric particles: a review of observations, J. Aerosol Sci., 35, 143-176, 2004b.

Kulmala, M., Lehtinen, K. E. J., and Laaksonen, A.: Cluster activation theory as an explanation of the linear dependence between formation rate of $3 \mathrm{~nm}$ particles and sulphuric acid concentration, Atmos. Chem. Phys., 6, 787-793, doi:10.5194/acp-6-787-2006, 2006.

Kulmala, M., Riipinen, I., Sipilä, M., Manninen, H. E., Petäjä, T., T., Junninen, H., Maso, M. D., Mordas, G., Mirme, A., and Vana, M.: Toward direct measurement of atmospheric nucleation, Science, 318, 89-92, 2007.

Kulmala, M., Asmi, A., Lappalainen, H. K., Carslaw, K. S., Pöschl, U., Baltensperger, U., Hov, Ø., Brenquier, J.-L., Pandis, S. N., Facchini, M. C., Hansson, H.-C., Wiedensohler, A., and O'Dowd, C. D.: Introduction: European Integrated Project on Aerosol Cloud Climate and Air Quality interactions (EUCAARI) - integrating aerosol research from nano to global scales, Atmos. Chem. Phys., 9, 2825-2841, doi:10.5194/acp-9-2825-2009, 2009.

Laaksonen, A., Hamed, A., Joutsensaari, J., Hiltunen, L., Cavalli, F., Junkermann, W., Asmi, A., Fuzzi, S., and Facchini, M. C.: Cloud condensation nucleus production from nucleation events at a highly polluted region, Geophys. Res. Lett., 6, L06812, doi:10.1029/2004GL022092, 2005.

Lehtinen, K. E. J. and Kulmala, M.: A model for particle formation and growth in the atmosphere with molecular resolution in size, Atmos. Chem. Phys., 3, 251-257, doi:10.5194/acp-3-251-2003, 2003.

Lehtinen, K. E. J., Dal Maso, M., Kulmala, M., and Kerminen, V. M.: Estimating nucleation rates from apparent particle formation rates and vice versa: Revised formulation of the KerminenKulmala equation, J. Aerosol Sci., 38, 988-994, 2007.

Mäkelä, J. M., Yli-Koivisto, S., Hiltunen, V., Seidl, W., Swietlicki,
E., Teinilä, K., Sillanpää, M., Koponen, I. K., Paatero, J., Rosman, K., and Hämeri, K.: Chemical composition of aerosol during particle formation events in boreal forest, Tellus B, 53, 380 393, 2001.

Manninen, H. E., Nieminen, T., Riipinen, I., Yli-Juuti, T., Gagné, S., Asmi, E., Aalto, P. P., Petäjä, T., Kerminen, V.-M., and Kulmala, M.: Charged and total particle formation and growth rates during EUCAARI 2007 campaign in Hyytiälä, Atmos. Chem. Phys., 9, 4077-4089, doi:10.5194/acp-9-4077-2009, 2009.

McMurry, P. H. and Friedlander, S. K.: New particle formation in the presence of an aerosol, Atmos. Environ., 13, 1635-1651, 1979.

McMurry, P. H.: Photochemical aerosol formation from $\mathrm{SO}_{2}$ : a theoretical analysis of smog chamber data, J. Colloid Interface Sci., 78, 513-527, 1980.

McMurry, P. H.: New particle formation in the presence of an aerosol: rates, time scales, and sub- $0.01 \mu \mathrm{m}$ size distributions, J. Colloid Interface Sci., 95, 72-80, 1983.

McMurry, P. H., Fink, M., Sakurai, H., Stolzenburg, M. R., Mauldin, R. L., Smith, J., Eisele, F., Moore, K., Sjostedt, S., Tanner, D., Huey, L. G., Nowak, J. B., Edgerton, E., and Voisin, D.: A criterion for new particle formation in the sulfur-rich Atlanta atmosphere, J. Geophys. Res., 110, D22S02, doi:10.1029/2005JD005901, 2005.

O’Dowd, C. D., Aalto, P., Hameri, K., Kulmala, M., and Hoffmann, T.: Atmospheric particles from organic vapours, Nature, 416, 497-498, 2002.

Petäjä, T., Mauldin, III, R. L., Kosciuch, E., McGrath, J., Nieminen, T., Paasonen, P., Boy, M., Adamov, A., Kotiaho, T., and Kulmala, M.: Sulfuric acid and $\mathrm{OH}$ concentrations in a boreal forest site, Atmos. Chem. Phys., 9, 7435-7448, doi:10.5194/acp9-7435-2009, 2009.

Rao, N. P. and McMurry, P. H.: Nucleation and growth of aerosol in chemically reacting systems, Aerosol Sci. Technol., 11, 120 132, 1989.

Riipinen, I., Sihto, S.-L., Kulmala, M., Arnold, F., Dal Maso, M., Birmili, W., Saarnio, K., Teinilä, K., Kerminen, V.-M., Laaksonen, A., and Lehtinen, K. E. J.: Connections between atmospheric sulphuric acid and new particle formation during QUEST III-IV campaigns in Heidelberg and Hyytiälä, Atmos. Chem. Phys., 7, 1899-1914, doi:10.5194/acp-7-1899-2007, 2007.

Riipinen, I., Manninen, H. E., Yli-Juuti, T., Boy, M., Sipilä, M., Ehn, M., Junninen, H., Petäjä, T., and Kulmala, M.: Applying the Condensation Particle Counter Battery (CPCB) to study the water-affinity of freshly-formed 2-9 nm particles in boreal forest, Atmos. Chem. Phys., 9, 3317-3330, doi:10.5194/acp-93317-2009, 2009.

Sihto, S.-L., Kulmala, M., Kerminen, V.-M., Dal Maso, M., Petäjä, T., Riipinen, I., Korhonen, H., Arnold, F., Janson, R., Boy, M., Laaksonen, A., and Lehtinen, K. E. J.: Atmospheric sulphuric acid and aerosol formation: implications from atmospheric measurements for nucleation and early growth mechanisms, Atmos. Chem. Phys., 6, 4079-4091, doi:10.5194/acp-6-4079-2006, 2006.

Sipilä, M., Lehtipalo, K., Attoui, M., Neitola, K., Petäjä, T., Aalto, P. P., O'Dowd, C. D., and Kulmala, M.: Laboratory verification of PH-CPC's ability to monitor atmospheric sub-3 nm clusters, Aerosol Sci. Technol., 43, 126-135, 2009.

Smith, J. N., Dunn, M. J., VanReken, T. M., Iida, K., Stolzenburg, 
M. R., McMurry, P. H., and Huey, L. G.: Chemical composition of atmospheric nanoparticles formed from nucleation in Tecamac, Mexico: evidence for an important role for organic species in nanoparticle growth, Geophys. Res. Lett., 4, L04808, doi:10.1029/2007GL032523, 2008.

Smith, J. N., Barsanti, K. C., Friedli, H. R., Ehn, M., Kulmala, M., Collins, D. R., Scheckman, J. H., Williams, B. J., and McMurry, P. H.: Observations of aminium salts in atmospheric nanoparticles and possible climatic implications, P. Natl. Acad. Sci., 15, 6634-6639, 2010.

Spracklen, D. V., Carslaw, K. S., Kulmala, M., Kerminen, V. M., Sihto, S.-L., Riipinen, I., Merikanto, J., Mann, G. W., Chipperfield, M. P., Wiedensohler, A., Birmili, W., and Lihavainen, H.: Contribution of particle formation to global cloud condensation nuclei concentrations, Geophys. Res. Lett., 35, L06808, doi:10.1029/2007GL033038, 2008.

Stolzenburg, M. R. and McMurry, P. H.: An ultrafine aerosol condensation nucleus counter, Aerosol Sci. Technol., 14, 48-65, 1991.

Stolzenburg, M. R., McMurry, P. H., Sakurai, H., Smith, J. N., Mauldin, R. L., Eisele, F. L., and Clement, C. F.: Growth rates of freshly nucleated atmospheric particles in Atlanta, J. Geophys. Res., 110, D22S05, doi:10.1029/2005JD005935, 2005.
Warren, D. R. and Seinfeld, J. H.: Simulation of aerosol size distribution evolution in systems with simultaneous nucleation, condensation, and coagulation, Aerosol Sci. Technol., 4, 31-43, 1985.

Weber, R. J., Marti, J. J., McMurry, P. H., Eisele, F. L., Tanner, D. J., and Jefferson, A.: Measured atmospheric new particle formation rates: Implications for nucleation mechanisms, Chem. Eng. Commun., 151, 53-64, 1996.

Weber, R. J., Marti, J. J., McMurry, P. H., Eisele, F. L., Tanner, D. J., and Jefferson, A.: Measurements of new particle formation and ultrafine particle growth rates at a clean continental site, J. Geophys. Res., 102(D4), 4375-4385, 1997.

Wehner, B., Petäjä, T., Boy, M., Engler, C., Birmili, W., Tuch, T., Wiedensohler, A., and Kulmala, M.: The contribution of sulfuric acid and non-volatile compounds on the growth of freshly formed atmospheric aerosols, Geophys. Res. Lett., 32, L17810, doi:10.1029/2005GL023827, 2005.

Woo, K. S., Chen, D. R., Pui, D. Y. H., and McMurry, P. H.: Measurement of Atlanta aerosol size distributions: observations of ultrafine particle events, Aerosol Sci. Technol., 34, 75-87, 2001.

Wu, J. and Flagan, R. C.: A discrete-sectional solution to the aerosol dynamic equation, J. Colloid Interface Sci., 123, 339-352, 1988. 